\title{
Prevalence of Bovine Cysticercosis at Jijiga Municipal Abattoir, Ethiopia
}

\section{Wolde Akalu Biruk*}

Ministry of Agriculture and Rural Development, Ethiopia

\begin{abstract}
The study was made from November 2008 to April 2009 at the Ethiopia Somali region, Jijiga city. It was carried out with the objectives of providing base line data on the prevalence of $C$. bovis. A total of 400 carcasses of randomly selected bovine animals were used for the active abattoir survey. Of the 400 carcasses examined during the study period, $9(2.25 \%)$ were infected with $C$. bovis. The distribution of organ infected with $C$. bovis were, tongue (55.5\%) and heart $(55.5 \%)$, shoulder muscle (33.3\%), masseter muscle $(22.2 \%)$, and liver (11.1\%). Analysis of active abattoir survey revealed that there was no a significant difference $(P>0.05)$ between sex and age of the animal. The viability test on all isolated cysts showed that $20 \%$ were viable. the tongue, shoulder muscle, masseter muscle and heart had the highest number of viable $(60 \%),(60 \%),(50 \%)$ and $(33.3 \%)$ cyst respectively. Meat inspection cannot totally prevent the consumer from being infected through row or under cocked meat/beef. Therefore, an effective control program has to include action intervening at various points of the life cycle of $T$. saginata. It requires an integrated approach among all stake holders: consumers, medical doctors and pharmacists, meat inspectors, veterinary practitioners and farmers.
\end{abstract}

Keywords: Prevalence; C. bovis; T. saginata; Jijiga

\section{Introduction}

Animal diseases are one of the most important constraints to increase productivity of food animals in all parts of the world. Parasitism is one of the major problems that affect the productivity of livestock worldwide. Among many parasitic problems of domestic animals, tapeworms are an economically important intestinal parasites found all over the world, which have infected human beings for thousands of years [1].

The nation's domestic meat consumption of about $45 \%$ comes from cattle, which generates export income mainly from the sale of live animals. In foreign trade, although the country is ideally placed to export live animals to the big markets of the Middle East and substantial markets of North and West Africa, export earning is relatively low. This is mainly due to the presence of a number of unimproved animal health problems, among which, Taenia saginata (T. saginata) or Cysticercus bovis (C. bovis) is one that remains a major public and animal health problem [2].

Transmission of the parasite occurs most commonly in the environment characterized by poor sanitation, primitive livestock husbandry practices and inadequate meat inspection management control police. Bovine cysticercosis is responsible for considerable amount of economic losses which can approach $30 \%$ when allowance is made for the loss in the carcass weight and the cost of freezing the infected meat. Generally the loss is determined by disease prevalence, grade of the animal infected, potential markets, prices of cattle treatment for detained carcass [3] and medical costs for infected human being [4]. The average annual loss due to taenicidal drugs for treatment in Ethiopia was estimated to be 4,937,583.21 Ethiopian birr [5,6].

Bovine cysitcercosis is widely distributed in Ethiopia and a number of individual reported the prevalence of bovine cysitcercosis in different parts of the country $2.25 \%$ reports of Tembo $(3.2 \%)$ and $(2.9 \%$ and 4.4\%) prevalence Jimma in south-western Ethiopia (Megersa et al.; Tolosa et al.) and Ziway (3.0\%) (Bedu et al.) in southern Ethiopia and (26.3\%) (Abunna et al.) in Hawasa and in north-western Ethiopia (18.5\%) (Kebede) [7-12].
On the other hand the contribution of Cysticercus bovis to organ condemnation in slaughtered cattle at different abattoir have been reported $[12,13]$. It is a great problem in developing country like Ethiopia due to the cultural habit eating raw meet as routine dish and holidays has promoted human taeniasis in Ethiopia. The above mentioned problems allow the parasite to continue its life cycle till to date and in the coming future (Ecker).

The objective of this particular research are:

- To determine the prevalence of bovine cysticercosis at Jijiga municipal abattoir

- To assess the viability of Cysticercus bovis cysts.

\section{Materials and Methods}

\section{Study area}

The study was conducted from November 2008 to April 2009 in Jijiga city. Jijiga which is the capital city of Ethiopia Somali region is found eastern part of Ethiopia $630 \mathrm{~km}$ away from Addis Ababa and 105 $\mathrm{km}$ of east of Harar city with population size of 105,634. Jijiga is situated at altitude of 1660 m.a.s.l, $9^{\circ} 20^{\circ}$ North Latitude and $45^{\circ} 56^{\circ}$ East Longitude. The climate of Jijiga is semi-arid type which is characterized by high temperature and low rain fall. The mean annual rain fall is about $543 \mathrm{~mm}$ and mean annual temperature is about $22^{\circ} \mathrm{C}$.

\section{Study population}

Active abattoir survey: 400 presented for slaughter at Jijiga municipal abattoir were examined for the presence of $C$. bovis following routine meat inspection procedure as per the ministry of agriculture

*Corresponding author: Wolde Akalu Biruk, Ministry of Agriculture and Rural Development, Ethiopia, Tel: 251116460746; E-mail: birukakalu97@gmail.com

Received March 29, 2017; Accepted April 05, 2017; Published April 06, 2017

Citation: Biruk WA (2017) Prevalence of Bovine Cysticercosis at Jijiga Municipa Abattoir, Ethiopia. J Vet Sci Technol 8: 442. doi: 10.4172/2157-7579.1000442

Copyright: @ 2017 Biruk WA. This is an open-access article distributed under the terms of the Creative Commons Attribution License, which permits unrestricted use, distribution, and reproduction in any medium, provided the original author and source are credited. 
meat inspection procedure regulation.

\section{Study design}

The type of study was cross sectional type of study which was used to determine the prevalence cysticercosis in the abattoir.

\section{Sample size}

Active abattoir survey: To determine the sample size require for the abattoir i used the $50 \%$ prevalence as expected prevalence of cysticercosis because of no previous prevalence data recorded and the formula for sample size determination (Thrusfield)

$$
n=\frac{1.96^{2}\left(P_{\exp }\left(1-P_{\exp }\right)\right.}{d^{2}}
$$

where $n=$ required sample size; $P_{\text {exp }}=$ expected prevalence; $d^{2}=$ desired absolute precision; By taking 50\% expected prevalence and 5\% desired absolute precision.

$$
\mathrm{n}=384
$$

To increase my sample size 400 cattle were examined.

\section{Study methodology}

Active abattoir survey: During the study period 400 bovine carcasses were randomly examined for the presence of C. bovis following the customary meat inspection procedure stipulated in the ministry of agriculture (MOA) meat inspection regulation. cattle slaughtered were mainly old age, few young and emaciated.

The study animals were originated from Jijiga and around Jijiga city. prior to sampling each selected animals was given an identification number and data on each animal sex, age and breed were recorded. during meat inspection, identified animal and their respective organs were strictly examined separately to avoid mixing up of organs meat inspection was made in accordance with the procedure of Ethiopian ministry of agriculture meat inspection regulation for detection of Cysticercus bovis. Visual inspection and palpation followed by multiple incision of in each organ (heart, tongue, shoulder, liver and masseter) were made to examine the cysts of $T$. saginata.

Each organ, which is going to be inspected, was subjected to the following dissection procedure:

In the head two linear incision in to the external masseter muscle and one into the internal on each side of the lower jaw and parallel to it. In the tongue one longitudinal incision in to the underside; in shoulder, one deep incision into the triceps brachial muscle above the olecranon process; in the heart, incision in to both the ventricle and septum; further incision is made if necessary.

During the survey, detailed record were kept in each one or more number of cysts, either dead or live cysts was recorded. the information recorded was date, age, sex and the number of cysts (live or dead) in the inspection sites, when the cyst had a thick connective tissue and which contain caseous and calcified material they were assessed as dead. Cyst with translucent capsule through which the white scolex could be seen were counted as live. Each caracass was aged based on the number of erupted permanent incisors teeth. The data were combined for analysis in to two age group, namely $\leq 6$ years and $>6$ years.

Viability test: Any cyst that was found at meat inspection was removed with the surrounding tissue taken to Jijiga regional veterinary diagnostic and research laboratory. then, the cyst were incubated at $37^{\circ} \mathrm{C}$ in $40 \%$ Ox-bile solution dissolved in normal saline for 1-2 hours. The cyst was regarded as viable if the scolex evaginated during the incubation period. Examination was performed under microscope after pressing betwen two glasses for scolex whether it was $T$. saginata or other metacestodes based on the size of cysticercus and absence of hooks ontherostlum of the evaginated cyst [14].

\section{Data management and analysis}

From data collected in active abattoir survey the total number of C. bovis was determined. The relative frequency of $C$. bovis in various sites was calculated. Distribution of calcified and non calcified cyst and Viability of C. bovis cyst was assessed. the data were put in excel sheet and analyzed STATA analytical software version 12.

\section{Results}

\section{Active abattoir survey}

Among the 400 slaughtered cattle examined during this study period $342(85.5 \%)$ and $58(14.5 \%)$ were male and female animals respectively of this animal $9(2.25 \%)$ were found to be infected with C. bovis under routine meat inspection.

The prevalence of $C$. bovis between different age groups animals is shown on Table 1. There was no significant difference among those age groups based on dental formulation. The percentage of infected carcass of male and female animals are presented in Table 2. There was no significant difference $(\mathrm{P}>0.05)$ among male and female animals slaughtered in the proportion of C. bovis infection (Tables 3-5).

\section{Viability test}

Viability test is presented in Table 6.

\section{Discussion}

During the abattoir survey conducted at Jijiga municipal abattoir the overall prevalence of bovine cysticercosis was indicated as $2.25 \%$ which is similar to the reports of Tembo (3.2\%) and (2.9\% and $4.4 \%)$ prevalence Jimma in south-western Ethiopia (Megersa et al.; Tolosa et al.) and Ziway (3.0\%) (Bedu et al.) in southern Ethiopia, extremely different from (26.3\%) (Abunna et al.) in Hawasa and in north-western Ethiopia (18.5\%) (Kebede) [7-12].

However, large differences can also be found within a region. In two studies conducted in and around Addis Ababa in central Ethiopia, prevalence varied between 7.5\% (Kebede, Tilahun and Hailu) and $89.4 \%$ (Tembo) $[9,12]$. Such differences in prevalence may be associated with the number of cattle examined, the sensitivity of the meat inspection procedures, which can be affected by the site and method of incision, abattoir facilities and management, the motivation and competency of the meat inspectors and the willingness of the owner to cooperate $[11,15]$.

\begin{tabular}{|c|c|c|}
\hline Age group & No. of carcass inspected & No. of infected carcass \\
\hline$>6$ years & $292(73 \%)$ & $7(77.7 \%)$ \\
\hline$\leq 6$ years & $108(27 \%)$ & $2(22.22 \%)$ \\
\hline$X^{2}=0.1066$ & $\mathrm{df}=1$ & $\mathrm{P}=0.744$ \\
\hline
\end{tabular}

Table 1: Prevalence of bovine cysticercosis in different age groups. 
Citation: Biruk WA (2017) Prevalence of Bovine Cysticercosis at Jijiga Municipal Abattoir, Ethiopia. J Vet Sci Technol 8: 442. doi: 10.4172/21577579.1000442

Page 3 of 4

\begin{tabular}{|c|c|c|}
\hline Sex & No. of carcass inspected & No. of infected carcass \\
\hline Female & 58 & $2(3.44 \%)$ \\
\hline Male & 342 & $7(2.05 \%)$ \\
\hline$X^{2}=0.4429$ & $\mathrm{df}=1$ & $\mathrm{p}=0.506$ \\
\hline
\end{tabular}

\begin{tabular}{|c|c|c|c|c|}
\hline Age group & Heart & Tongue & Shoulder muscle & Masseter muscle \\
\hline$>6$ years & 4 & 4 & 1 & 1 \\
\hline$\leq 6$ years & 1 & 2 & 2 & 1 \\
\hline Total & $5(55.5 \%)$ & $6(88.8 \%)$ & $3(33.5 \%)$ & 1 \\
\hline
\end{tabular}

Table 3: Distribution and frequency of $C$. bovis cyst infected cattle in relation with age and organ affected in positive animals.

\begin{tabular}{|c|c|c|c|}
\hline & $>6$ years & $\leq 6$ years & Total \\
\hline Total no. of animals examined & 292 & 108 & 400 \\
\hline No. of cysticercus recovered & 17 & 9 & 26 \\
\hline Heart & 4 & 3 & $7(26.92 \%)$ \\
\hline Tongue & 6 & 3 & $9(34.01 \%)$ \\
\hline Shoulder muscle & 5 & 1 & $6(23.07 \%)$ \\
\hline Masseter muscle & 1 & 2 & $3(11 / 53 \%)$ \\
\hline Liver & 1 & 0 & $1(3.84 \%)$ \\
\hline
\end{tabular}

Table 4: Infection with $C$. bovis in the organs of cattle with different age group during the study period.

\begin{tabular}{|c|c|c|c|c|}
\hline Nature of the cyst & Heart & Tongue & Shoulder muscle & Masseter muscle \\
\hline Calcified & $4(36.36 \%)$ & $4(36.36 \%)$ & $1(9.09 \%)$ & $1(9.09 \%)$ \\
\hline Non calcified & 3 & 5 & 5 & 2 \\
\hline Total & 7 & 9 & 6 & 3 \\
\hline
\end{tabular}

Table 5: Distribution of calcified and non calcified cyst.

\begin{tabular}{|c|c|c|c|}
\hline Infected organs & No. of cysts examined & No. of viable cysts \\
\hline Heart & 3 & 1 & 3 \\
\hline Tongue & 5 & 3 & $33.3 \%$ \\
\hline Shoulder muscle & 5 & 1 & $60 \%$ \\
\hline Masseter muscle & 2 & $50 \%$ & \\
\hline Liver & 1 & $50 \%$ & \\
\hline
\end{tabular}

Table 6: Viability of $C$. bovis cyst in the laboratory study.

The geographical differences in the habit of raw meat consumption, environmental and personal hygiene, animal husbandry practices, proximity to waste water and accessibility of taenicides for treating animals might also contribute to differences in prevalence [15-17]. In this study it is found that sex and age has no association $(\mathrm{p}>0.05)$ with C. bovis prevalence in the selected cattle, it revealed that no significant risk factor for the infection of bovine cysticercosis among the animal slaughtered at Jijiga municipal abattoir. The organ wise prevalence of each organ in the abattoir survey (Jijiga) was found being in the tongue highly prevalent $6(88.8 \%)$, heart $5(55.5 \%)$, shoulder muscle $3(33.5 \%)$, masseter muscle $2(22.2 \%)$ and liver $1(11.1 \%)$.

The most frequently affected organ was the tongue followed by heart and other organs which is similar were compared with Dawit, Viability test showed that tongue and shoulder muscle had the highest relative frequency proportion of viable cyst $3(60 \%)$ followed by masseter muscle and heart $1(50 \%)$ and $1(33.3 \%)$ respectively [6]. The method of meat inspection, the ability of the meat inspector to identify the cases, different in management, sample size, sampling method and the number of cuts, and other factors can contribute for the variation of the prevalence of bovine cysticercosis.

\section{Conclusion and Recommendation}

T. saginata is a medically and economically important cestode parasite, while in cattle causes economic loss in the meat industry. In this study, the prevalence of bovine cysticercosis was relatively lower than the reports by different researchers in different parts of the country.

Among the potential risk factors, religion, occupation and consumption of raw meat were very risk factors for taeniasis. Based on the finding of the present study, the following are recommended.

- Farmers should be fully supported and informed of the life cycle of T. saginata and potential risk factors for cattle to become infected.

- There should be a public awareness about the health and economic significance the disease.

- Infected meat and meat products must undergo the process of freezing, boiling or distraction of the cysticerci based on the intensity of infection.

- Improvement in working condition of the inspectors with upgrading their skill and working conditions.

\section{References}

1. Thrusfield M (1995) Veterinary epidemology. 2nd edn. Blackwell Science Ltd. UK, pp: 182-198.

2. Radostits OM, Blood DC, Gay CC, Hinchcliff KW, Constable PD (2007) Veterinary Medicine. Text book of the disease of cattle, sheep, goat. pig and horses. 10th edn. Saunders, Philadelphia, pp: 1581-1583. 
Citation: Biruk WA (2017) Prevalence of Bovine Cysticercosis at Jijiga Municipal Abattoir, Ethiopia. J Vet Sci Technol 8: 442. doi: 10.4172/21577579.1000442

Page 4 of 4

3. Mekbib B, Abesha H, Tesfaye D (2013) Study on Zoonotic Metacestodes of Cattle Slaughtered at Bahir Dar Municipal Abattoir, Northwest Ethiopia. Global Veterinaria 10: 592-598.

4. Gruindle RG (1978) Economic loss resulting from bovine cysticercosis with special reference Botswana and Kenya. Trop Anim Health Prod 10: 127-140.

5. Fan PC (1997) Annual Economic loss caused by Taenia saginata taeniasis in East Asia. Parasitol Today 13: 194-135.

6. Dawit S (2004) Epidemiology of T. saginata taeniasis and Cysticercosis in North Gonder Zone. DVM Thesis, Faculty of Veterinary Medicine, Addis Ababa University, Debre Zeit, Ethiopia.

7. Fufa A (2006) Study on the prevalence of Bovine cysticercosis in Awassa Municipal Abattoir and Taenia saginata in Awassa town and its surrounding, Southern Ethiopia. MSc Thesis, Addis Ababa University, Debre Zeit, Ethiopia.

8. Tembo A (2001) Epidemiology of $T$. saginata taeniasis and cysticercosis in three selected agro-climatic zones in central Ethiopia. MSc Thesis, Faculty of Veterinary Medicine, Addis Ababa University, Debre Zeit, Ethiopia

9. Megersa B, Tesfaye E, Regassa A, Abebe R, Abunna F (2010) Bovine cysticercosis in cattle slaughtered at jimma municipal Abattoir, South Western ethiopia: prevalence, cyst viability and its socio economic importance. Vet World 3: 257-262.

10. Tolosa T, Tigre W, Teka G, Dorny P (2009) Prevalence of bovine cysticercosis and hydatidosis in Jimma municipal abattoir, South West Ethiopia Onderstepoort J Vet Res 76: 323-326.

11. Bedu H, Tafess K, Shelima B, Woldeyohannes D, Amare B (2011) Bovine cysticercosis in cattle slaughtered at Zeway municipal Abattoir: prevalence and its public health importance. J Vet Sci Technol 2: 108.

12. Abunna F, Tilahun G, Bersisa K, Megersa B, Regassa A (2008) Bovine cysticercosis in cattle slaughtered at Awassa municipal abattoir, Ethiopia: prevalence, cyst viability, distribution and its public health implication. Zoonoses and public health 55 : $82-88$.

13. Kebede N, Tilahun G, Hailu A (2009) Current Status of Bovine Cysticercosis of Slaughtered Cattle in Addis Ababa Abattoir, Ethiopia. Trop Anim Health Prod 41: 291-294.

14. Fekadu D (2003) A study on cestodes and metacestodes of sheep in sheno agricultural Research (SHARC), Northern shoa. DVM Thesis, Faculty of Veterinary Medicine, Addis Ababa University, Debre Zeit, Ethiopia.

15. Gracey FJ, Collins SD, Hucy RJ (1999) Meat Hygiene. 10th edn. Bailliere Tindall, 24-28 oval roads, London NW 17DX, UK, pp: 413-420.

16. Wanzala W, Onyango-Abuje JA, Kang'Ethe EK, Zessin KH, Kyule NM, et al (2003) Analysis of Post-Mortem Diagnosis of Bovine Cysticercosis in Kenyan Cattle. J Vet Res 7: 1-9.

17. Kumar A, Tadesse G (2011) Bovine cysticercosis in Ethiopia: a review. Ethiop. Vet J 15: 15-35. 